\title{
OPTIMIZATION OF SKELETAL CONFIGURATION: STUDIES OF SCOLIOSIS CORRECTION BIOMECHANICS
}

\author{
George T. Wynarsky and Albert B. Schultz* \\ Department of Mechanical Engineering and Applied Mechanies, University of Michigan, Ann Arbor, \\ MI 48109-2125, U.S.A.
}

\begin{abstract}
A scheme for optimizing configurations in models of skeletal structures is presented. Use of the scheme is illustrated through determination of biomechanically optimal correction of a right-thoracic scoliosis by passive brace and active muscle forces. The locations and magnitudes of the passive brace forces, and the trunk muscle groups and their corresponding contraction intensity magnitudes that would optimally correct the geometric deformities of the spine were determined. The results suggest that, from a biomechanical viewpoint, both brace and muscle forces are capable of substantial correction of a model thoracic scoliosis. However, comparison of model results with long-term clinical results suggests that even under optimal conditions it is unlikely that scoliosis can be fully corrected by passive brace forces or active muscle contractions.
\end{abstract}

\section{INTRODUCTION}

Bracing remains the most common method of nonoperative treatment of idiopathic scoliosis (Benson, 1987; Lonstein and Winter, 1988; Kehl and Morrissy, 1988; Keller, 1989; Gunnoe, 1990). Two current views as to how bracing corrects scoliosis are that (1) correction is produced by passive response to the forces applied by the brace; or (2) brace-wearing engenders active contractions of trunk muscles, and those muscle forces correct the scoliosis. Moreover, some cases of scoliosis are treated conservatively by electrostimulation of muscles on the convex side of the scoliotic curve (Bobechko et al., 1979; Axelgaard and Brown, 1983; Axelgaard et al., 1983; Brown et al., 1984). We undertook studies to examine what passive brace and active muscle contraction forces would be required to produce biomechanically optimal correction of a spine with a scoliosis curve. These studies examined (1) to what extent a scoliosis can be corrected when corrective forces are optimally selected; and (2) what sets of passive brace or active muscle forces produce those optimal corrections.

A number of structural models suitable for studies of skeletal configurations exist, generally consisting of a collection of rigid bodies to represent the bony elements of the skeleton, interconnected by a series of deformable elements to represent the soft tissues. Forces and moments are applied to the models, and their resulting displacements and rotations are computed. Such models have been used to study the biomechanics of correction of scoliosis, for example by Harrington instrumentation (Schultz and Hirsch, 1973a), by Milwaukee brace (Andriacchi et al., 1976), and by muscle stimulation (Schultz et al., 1981). Beamcolumn structural models have been used to analyse a

Received in final form 10 January 1991

*Author to whom correspondence should be addressed. functional scoliosis (Lindbeck, 1985) and curve progression and orthotic stabilization in idiopathic scoliosis (Patwardhan et al., 1986). Ghista et al. (1988) used a two-dimensional finite element model of the spine to determine the axial distraction and lateral traction forces required for optimal correction of scoliosis by spinal instrumentation. These models have not so far been used to examine optimal correction by bracing.

The primary purpose of this paper is to describe a computational technique to optimize configurations of rigid-body deformable-element models of the skeleton. The technique has general applicability, but its use will be illustrated here through finding sets of brace and trunk muscle forces that produce biomechanically optimal, non-surgical correction of a scoliosis.

\section{METHODS}

The effects of passive brace forces and active muscle contractions were simulated in an existing computer model of the spine and rib cage (Belytschko et al., 1973; Schultz et al., 1973b; Andriacchi et al., 1974; Schultz et al., 1974a, b; Takashima et al., 1979). This model incorporated 39 rigid bodies to represent the vertebrae of the thoracic and lumbar spine, the sacrum, rib pairs $1-10$, and the sternum. These 39 rigid bodies were interconnected by 236 spring and 59 beam deformable elements to represent the soft tissues of the motion segments, the costal cartilages and other ligamentous tissues of the trunk. Each spring element was characterized by one axial stiffness and each beam element by six stiffnesses; one each for axial deformation, torsional rotation, lateral bending, lateral shear, anteroposterior bending and anteroposterior shear. Skeletal geometries and soft-tissue property data were those from the background papers cited. Trunk muscles capable of applying significant forces to the spine or rib cage were represented by 78 model muscle slips 
(Table 1, column 1), using the techniques of Takashima et al. (1979) with minor modifications to their data (revised locations of muscle origins, insertions, and lines-of-action). In all computations, the sacrum was fully fixed while the vertebrae, ribs, and sternum were free to displace and rotate within prescribed bounds. Since the initial scoliotic spine configuration was taken as an equilibrium configuration, the model spine was not axially loaded. The balancing of body weight by muscle and connective tissue actions would superpose on the results to be described, since the force-deformation behavior of the model used was assumed to be linear.

Table 1. Left column: muscle groups included in model with corresponding cross-sectional areas. Right column: muscle slips and corresponding contraction intensity magnitudes selected by the optimization program (objective function $A$ ) for correction of the mid-thoracic scoliosis

\begin{tabular}{|c|c|c|}
\hline Muscle name & $\begin{array}{l}\text { Area } \\
\left(\mathrm{cm}^{2}\right)\end{array}$ & $\begin{array}{l}\text { Contraction } \\
\text { intensity } \\
\left(\mathrm{Ncm}^{-2}\right)\end{array}$ \\
\hline $\begin{array}{l}\text { Midline erector } \mathbf{L} \\
\text { Midline erector } \mathbf{H}\end{array}$ & $\begin{array}{r}13.2 \\
5.6\end{array}$ & \\
\hline $\begin{array}{l}\text { Lt. thoracic erector } H \\
\text { Lt. thoracic erector } M \\
\text { Lt. lumbar-thoracic erector }\end{array}$ & $\begin{array}{r}6.9 \\
6.0 \\
15.0\end{array}$ & 10.0 \\
\hline $\begin{array}{l}\text { Rt. thoracic erector } \mathbf{H} \\
\text { Rt. thoracic erector } \mathbf{M} \\
\text { Rt. lumbar-thoracic erector }\end{array}$ & $\begin{array}{r}6.9 \\
6.0 \\
15.0\end{array}$ & 10.0 \\
\hline $\begin{array}{l}\text { Lt. rectus abdominis } \\
\text { Rt. rectus abdominis }\end{array}$ & $\begin{array}{l}3.9 \\
3.9\end{array}$ & 2.1 \\
\hline $\begin{array}{l}\text { Lt. external abdominal oblique } \mathbf{H} \\
\text { Lt. external abdominal oblique } \mathbf{M} \\
\text { Lt. external abdominal oblique } \mathbf{L}\end{array}$ & $\begin{array}{l}2.6 \\
3.2 \\
3.8\end{array}$ & $\begin{array}{r}8.2 \\
10.0\end{array}$ \\
\hline $\begin{array}{l}\text { Rt. external abdominal oblique } H \\
\text { Rt. external abdominal oblique } M \\
\text { Rt. external abdominal oblique } L\end{array}$ & $\begin{array}{l}2.6 \\
3.2 \\
3.8\end{array}$ & $\begin{array}{l}10.0 \\
10.0\end{array}$ \\
\hline $\begin{array}{l}\text { Lt. internal abdominal oblique } H \\
\text { Lt. internal abdominal oblique } M \\
\text { Lt. internal abdominal oblique } L\end{array}$ & $\begin{array}{l}3.9 \\
3.2 \\
3.8\end{array}$ & $\begin{array}{r}4.3 \\
10.0\end{array}$ \\
\hline $\begin{array}{l}\text { Rt. internal abdominal oblique } \mathbf{H} \\
\text { Rt. internal abdominal oblique } M \\
\text { Rt. internal abdominal oblique } L\end{array}$ & $\begin{array}{l}3.9 \\
3.2 \\
3.8\end{array}$ & 4.2 \\
\hline $\begin{array}{l}\text { Lt. pectoral major } \mathbf{H} \\
\text { Lt. pectoral major } \mathrm{L} \\
\text { Lt. pectoral minor }\end{array}$ & $\begin{array}{l}7.4 \\
6.5 \\
1.6\end{array}$ & $\begin{array}{l}10.0 \\
10.0\end{array}$ \\
\hline $\begin{array}{l}\text { Rt. pectoral major } \mathrm{H} \\
\text { Rt. pectoral major } \mathrm{L} \\
\text { Rt. pectoral minor }\end{array}$ & $\begin{array}{l}7.4 \\
6.5 \\
1.6\end{array}$ & \\
\hline $\begin{array}{l}\text { Lt. psoas major } \\
\text { Rt. psoas major }\end{array}$ & $\begin{array}{l}11.6 \\
11.6\end{array}$ & \\
\hline $\begin{array}{l}\text { Lt. trapezius } \mathbf{H} \\
\text { Lt. trapezius } \mathbf{M} \\
\text { Lt. trapezius } \mathbf{L}\end{array}$ & $\begin{array}{l}2.4 \\
2.4 \\
1.9\end{array}$ & $\begin{array}{r}10.0 \\
10.0 \\
9.1\end{array}$ \\
\hline $\begin{array}{l}\text { Rt. trapezius } \mathrm{H} \\
\text { Rt. trapezius } \mathrm{M} \\
\text { Rt. trapezius } \mathrm{L}\end{array}$ & $\begin{array}{l}2.4 \\
2.4 \\
1.9\end{array}$ & \\
\hline
\end{tabular}

Table 1. (Contd.)

\begin{tabular}{|c|c|c|}
\hline Muscle name & $\begin{array}{l}\text { Area } \\
\left(\mathrm{cm}^{2}\right)\end{array}$ & $\begin{array}{l}\text { Contraction } \\
\text { intensity } \\
\left(\mathrm{N} \mathrm{cm}^{-2}\right)\end{array}$ \\
\hline $\begin{array}{l}\text { Lt. latissimus } H \\
\text { Lt. latissimus } M \\
\text { Lt. latissimus } L\end{array}$ & $\begin{array}{l}1.5 \\
2.7 \\
3.5\end{array}$ & 10.0 \\
\hline $\begin{array}{l}\text { Rt. latissimus } \mathrm{H} \\
\text { Rt. latissimus } \mathrm{M} \\
\text { Rt. latissimus } \mathrm{L}\end{array}$ & $\begin{array}{l}1.5 \\
2.7 \\
3.5\end{array}$ & 10.0 \\
\hline $\begin{array}{l}\text { Lt. serratus H } \\
\text { Lt. serratus M } \\
\text { Lt. serratus L }\end{array}$ & $\begin{array}{l}3.7 \\
7.9 \\
4.9\end{array}$ & $\begin{array}{r}0.3 \\
9.8 \\
10.0\end{array}$ \\
\hline $\begin{array}{l}\text { Rt. serratus } \mathbf{H} \\
\text { Rt. serratus } \mathbf{M} \\
\text { Rt. serratus L }\end{array}$ & $\begin{array}{l}3.7 \\
7.9 \\
4.9\end{array}$ & $\begin{array}{l}10.0 \\
10.0\end{array}$ \\
\hline $\begin{array}{l}\text { Lt. intercostals } \mathbf{H} \\
\text { Lt. intercostals M } \\
\text { Lt. intercostals L }\end{array}$ & $\begin{array}{l}8.6 \\
8.4 \\
6.3\end{array}$ & 10.0 \\
\hline $\begin{array}{l}\text { Rt. intercostals } \mathbf{H} \\
\text { Rt. intercostals } \mathbf{M} \\
\text { Rt. intercostals L }\end{array}$ & $\begin{array}{l}8.6 \\
8.4 \\
6.3\end{array}$ & $\begin{array}{l}10.0 \\
10.0\end{array}$ \\
\hline $\begin{array}{l}\text { Lt. transverse abdominal } \mathbf{H} \\
\text { Lt. transverse abdominal } \mathbf{M} \\
\text { Lt. transverse abdominal } \mathrm{L}\end{array}$ & $\begin{array}{l}3.4 \\
3.4 \\
3.4\end{array}$ & $\begin{array}{r}10.0 \\
3.0 \\
0.6\end{array}$ \\
\hline $\begin{array}{l}\text { Rt. transverse abdominal } \mathbf{H} \\
\text { Rt. transverse abdominal } \mathbf{M} \\
\text { Rt. transverse abdominal } \mathbf{L}\end{array}$ & $\begin{array}{l}3.4 \\
3.4 \\
3.4\end{array}$ & $\begin{array}{l}10.0 \\
10.0\end{array}$ \\
\hline $\begin{array}{l}\text { Lt. quadratus lumborum } \\
\text { Rt. quadratus lumborum }\end{array}$ & $\begin{array}{l}2.6 \\
2.6\end{array}$ & 10.0 \\
\hline
\end{tabular}

$\mathrm{Lt}$. = left; $\mathrm{Rt}$. = right; $\mathrm{H}=$ high; $M=$ mid, $\mathrm{L}=$ low.

The basic structural computational technique employed was the direct-stiffness method. Model behavior is governed by the set of simultaneous linear algebraic equations

$$
[K]\{D\}=\{F\}
$$

where $[K]$ is the assembled global stiffness matrix that represents the geometric and material properties of the model, $\{D\}$ is a column vector of the global three displacements and three rotations of each model rigid body, and $\{F\}$ is a column vector of the global three force and three moment components applied to each rigid body. The number of equations, $N$, is six times the number of rigid bodies included in the model, or 234 here.

In this study, the $N$ global components of the applied loads $\{F\}$ consisted of those due to $N_{\mathrm{b}}$ brace forces and $N_{\mathrm{m}}$ muscle contraction intensities, so that equation (1) took the form

$$
[K]\{D\}=[C B]\left\{F_{\mathrm{b}}\right\}+[C M]\left\{F_{\mathrm{m}}\right\}
$$

where $[C B]$ is a prescribed $N \times N_{\mathrm{b}}$ matrix specifying the locations and directions of any applied brace forces, $\left\{F_{\mathrm{b}}\right\}$ the vector of brace force magnitudes, [CM] is a prescribed $N \times N_{\mathrm{m}}$ matrix specifying muscle 
lines-of-action and cross-sectional areas, and $\left\{F_{\mathrm{m}}\right\}$ the vector of muscle contraction intensities. Since the brace forces $\left\{F_{b}\right\}$, the muscle contraction intensities $\left\{F_{\mathrm{m}}\right\}$, and the translations and rotations of the rigid bodies $\{D\}$ were all unknown, equation (2) was highly indeterminate. Solutions were therefore obtained by optimization techniques.

The optimization problem took the general form

$$
\text { minimize an objective function } Q
$$

subject to

$$
\left[\begin{array}{l}
K-C B \\
-C M
\end{array}\right]\left\{\begin{array}{c}
D \\
\hdashline \mathbf{F}_{\mathrm{b}} \\
\hdashline \mathbf{F}_{\mathrm{m}}
\end{array}\right\}=\{0\}
$$

and lower and upper bounds on the force and displacement variables

$$
l_{i} \leqslant x_{i} \leqslant u_{i}
$$

where equation (3b) is a rearrangement of equation (2).

\section{Brace force vector $\left\{\mathrm{F}_{b}\right\}$}

The forces exerted by a Boston brace were represented by a network of $N_{\mathrm{b}}=196$ potential point loads, evenly distributed over the patient-orthosis contact surface. Point loads were located at the centers of $10.0 \mathrm{~cm}^{2}$ contact areas. Since braces seldom exert significant shear forces, each point load was assumed to act normal to the body surface. Brace forces were assumed to be transmitted directly to the rib cage in the thoracic region and directly to the vertebrae in the lumbar region. Force transmission through soft tissue (lumbar region) was also considered by assuming that a fraction of the extcrnal force was transmitted to the vertebrae. Since brace force locations and directions were prescribed, only the 196 brace force magnitudes were unknown.

\section{Muscle contraction intensity $\left\{\mathrm{F}_{m}\right\}$}

Following Takashima et al. (1979), each muscle slip was modelled using a series of secondary nodes run from origin to insertion. Secondary nodes not attached directly to a model rigid body were assumed to be rigidly linked to the vertebra closest to their superior-inferior level. Muscle slip contraction was represented by the application of equal and opposite forces to each node pair along the line of action. With muscle lines-of-action and cross-sectional areas prescribed, only the $N_{\mathrm{m}}=78$ contraction intensity magnitudes were unknown.

\section{Objective functions $\mathrm{Q}$}

The objective functions to be minimized were constructed using the geometric parameters that describe the spine deformity. The results of initial computational studies (Wynarsky, 1988) led to the exclusion of force parameters in the objective functions. Although each vertebral body had six degrees of freedom (three displacements and three rotations), only four of these
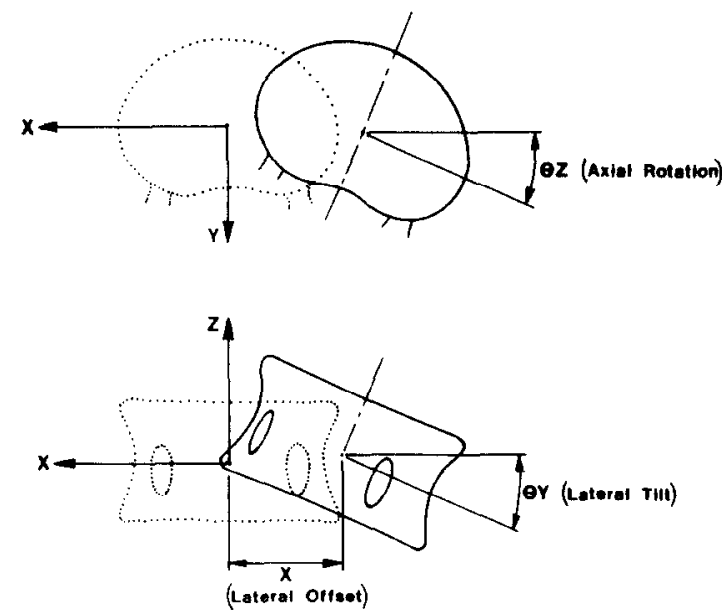

Fig. 1. The geometric components of scoliosis. Superior and posterior views of a normal (dotted) and displaced vertebra.

were included in the objective function. The geometric parameters were the lateral and anteroposterior global coordinates of the primary nodes of a model vertebra, represented by $X$ and $Y$, and the lateral and axial global orientations of that body, represented by $\theta_{y}$ and $\theta_{z}$. Vertebrae included in a scoliosis curve would have a lateral offset $X$, a lateral tilt $\theta_{y}$ (related to the Cobb angle of the curve), and an axial rotation $\theta_{z}$ (Fig. 1), while those in a structurally normal spine would have small or zero values for these variables. The $Y$ terms were included in the objective function to prevent displacements in the sagittal plane rather than displacements to correct the scoliosis. Geometric parameters for the rigid bodies other than the vertebrae were not included in the objective functions.

The vector of displacements in equation (3b) does not involve three out of the four geometric parameters directly. Rather, it involves small changes in these parameters, where the parameters, their initial values, and the changes that occur in them are given by

$$
\begin{aligned}
& X=X_{0}+\mathrm{d} X \\
& \theta_{y}=\theta_{y_{0}}+\mathrm{d} \theta_{y} \\
& \theta_{z}=\theta_{z_{0}}+\mathrm{d} \theta_{z} .
\end{aligned}
$$

Since the $Y$ coordinate (sagittal plane) differences between a normal model spine and a thoracic scoliosis model spine were small, the anteroposterior displacements were dealt with directly in the form of $d Y$. Thus, $\mathrm{d} X, \mathrm{~d} Y, \mathrm{~d} \theta_{y}$ and $\mathrm{d} \theta_{z}$ were the elements of the displacement vector for each vertebra in the model. Those displacements were to take on values such that the final vertebral configuration in terms of parameters $X$, $Y(\operatorname{ord} Y), \theta_{y}$, and $\theta_{z}$ was optimized. The initial values $X_{0}, \theta_{y_{0}}$, and $\theta_{z_{0}}$ were prescribed based on the original spine configuration for the specific configuration of scoliosis studied.

Because the geometric variables $X, Y, \theta_{y}$, and $\theta_{z}$ could take on either positive or negative values, the sum of the squares of these variables was minimized. 
This made the objective function a convex function subject to linear inequality constraints, which guaranteed that a global optimum would be found (Murtagh and Saunders, 1983).

To eliminate dimensional dependencc, the sums of the squares of the $X, \mathrm{~d} \theta_{y}$ and $\mathrm{d} \theta_{z}$ were divided by the sum of the squares of the initial vertebral body offsets or rotations [equation (5)]. Values of $\mathrm{d} Y(A-P$ displacements) remained small, so that normalization of these terms was not necessary. The sums were also weighted, as will subsequently be detailed.

In summary, the objective functions minimized the weighted sums of the squares of the major geometric components of the scoliosis deformities:

$$
\begin{aligned}
Q= & C_{1} \frac{\sum_{i=1}^{N_{v}}\left(X_{0}+\mathrm{d} X\right)_{i}^{2}}{\sum_{i=1}^{N_{v}}\left(X_{0}\right)_{i}^{2}}+C_{2} \sum_{i=1}^{N_{v}} \mathrm{~d} Y_{i}^{2} \\
& +C_{3} \frac{\sum_{i=1}^{N_{v}}\left(\theta_{y_{0}}+\mathrm{d} \theta_{y}\right)_{i}^{2}}{\sum_{i=1}^{N_{v}}\left(\theta_{y_{0}}\right)_{i}^{2}}+C_{4} \frac{\sum_{i=1}^{N_{v}}\left(\theta_{z_{0}}+\mathrm{d} \theta_{z}\right)_{i}^{2}}{\sum_{i=1}^{N_{v}}\left(\theta_{z_{0}}\right)_{i}^{2}}
\end{aligned}
$$

where $X$ is the lateral coordinates, $\mathrm{d} Y$ the anteroposterior displacements, $\theta_{y}$ the lateral tilts, $\theta_{z}$ the axial rotations, $N_{\mathrm{v}}$ the total number of vertebral bodies, and $C_{1}, C_{2}, C_{3}$, and $C_{4}$ are weighting coefficients.

\section{Selection of weighting coefficients}

Ideal correction of a scoliosis curve in an upright spine would bring all lateral offsets, lateral tilts, and axial rotations to zero and keep anteroposterior displacements reasonably small. Within the constraints used in these studies, ideal correction cannot be achieved. When correction cannot be ideal, what precisely constitutes optimal correction? Lateral tilts, lateral offsets and axial rotations clearly should be made as small as possible. But, is it more important to correct lateral tilts than axial rotations? So, to at least a small degree, the choice of objective function weightings is a matter of clinical judgement. Once those weightings are chosen, the computational techniques used here insure that the solutions obtained will be globally optimal.

To choose sets of weighting coefficients that would produce clinically pleasing spine final configurations, analyses were conducted in which each weighting coefficient was systematically varied over values from 1 to 100 (Wynarsky, 1988). The resulting configurations were visually judged. The most pleasing overall corrections were attained by weighting $X$ modestly, $Y$ minimally, and $\theta_{y}$ heavily. Changes in $\theta_{z}$ weighting had little visual impact, so a wider range of its values was ultimately explored. Based on the results, three sets of weightings $\left[C_{1}, C_{2}, C_{3}\right.$ and $C_{4}$ in equation (5) $]$ were examined in detail:

$$
\begin{aligned}
& Q_{A}=10 \mathrm{f}(X)+1 \mathrm{f}(Y)+50 \mathrm{f}\left(\theta_{y}\right)+2 \mathrm{f}\left(\theta_{z}\right) \\
& Q_{B}=10 \mathrm{f}(X)+1 \mathrm{f}(Y)+50 \mathrm{f}\left(\theta_{y}\right)+10 \mathrm{f}\left(\theta_{z}\right)
\end{aligned}
$$

$$
Q_{C}=20 \mathrm{f}(X)+1 \mathrm{f}(Y)+90 \mathrm{f}\left(\theta_{y}\right)+50 \mathrm{f}\left(\theta_{z}\right)
$$

where $\mathrm{f}(X), \mathrm{f}(Y), \mathrm{f}\left(\theta_{y}\right)$, and $\mathrm{f}\left(\theta_{z}\right)$ represent the summation terms in equation (5).

Successively greater emphasis was placed on decreasing the final axial rotations in weightings $A, B$, and $C$, respectively.

\section{Bounds on variables}

The maximum initial lateral offset in any case of scoliosis studied was $4.0 \mathrm{~cm}$, and the maximum initial vertebral rotation was $25^{\circ}$. Based upon these numbers, rigid body translations were arbitrarily limited to $10 \mathrm{~cm}$ and rigid body rotations to $90^{\circ}$. These bounds were not approached.

Based upon previously established skin pressure tolerances (Blount and Moe, 1973; Bunch, 1975; Bader and Gant, 1985) and brace-patient interface pressures measured by Chase et al. (1989) and Wynarsky (1988), brace point force magnitudes were kept within $10 \mathrm{~N}$ each, corresponding to pressures of $10 \mathrm{kPa}$ over the $10 \mathrm{~cm}^{2}$ areas. To account for non-maximal brace pressures, brace point force bounds of 2.5, 5.0, 7.5, and $10.0 \mathrm{~N}$ were explored.

Maximum voluntary muscle contraction intensities have been estimated to range from 400 to $1000 \mathrm{kPa}$ (Ikai and Fukunaga, 1968) in healthy adult males and to be approximately $200 \mathrm{kPa}$ in healthy adolescent females (Portillo et al., 1982). Accordingly, contraction intensities were kept within $100 \mathrm{kPa}$. Muscle intensity bounds of $25,50,75$, and $100 \mathrm{kPa}$ were explored.

\section{Optimization routine}

Optimizations were carried out using the modular in-core non-linear optimization system (MINOS) of Murtagh and Saunders $(1978,1983)$. This is a largescale optimization system for the solution of sparse linear and non-linear programs. For a linearly constrained non-linear (objective function) problem, MINOS uses a reduced-gradient algorithm in conjunction with a quasi-Newton algorithm based on the primal simplex method. To examine the effects on correction of only passive brace forces, the routine found the brace-force locations and corresponding magnitudes which yielded optimal correction in light of the selected weighting coefficients and the bounds on the variables. To examine the effects on correction of only active muscle forces, the routine found the muscles and their corresponding contraction intensities which yielded optimal correction. Combinations of both passive brace and active muscle forces within the prescribed bounds were also explored.

\section{Initial scoliosis morphology}

The computational method described here could be applied to any initial spine configuration. The initial morphology of the scoliosis curve for which results will be reported here was that of a typical right midthoracic curve (MT spine). This type of curve has the highest incidence (Moe and Kettleson, 1970). The initial curve configuration (Fig. 2) had its apex at the 

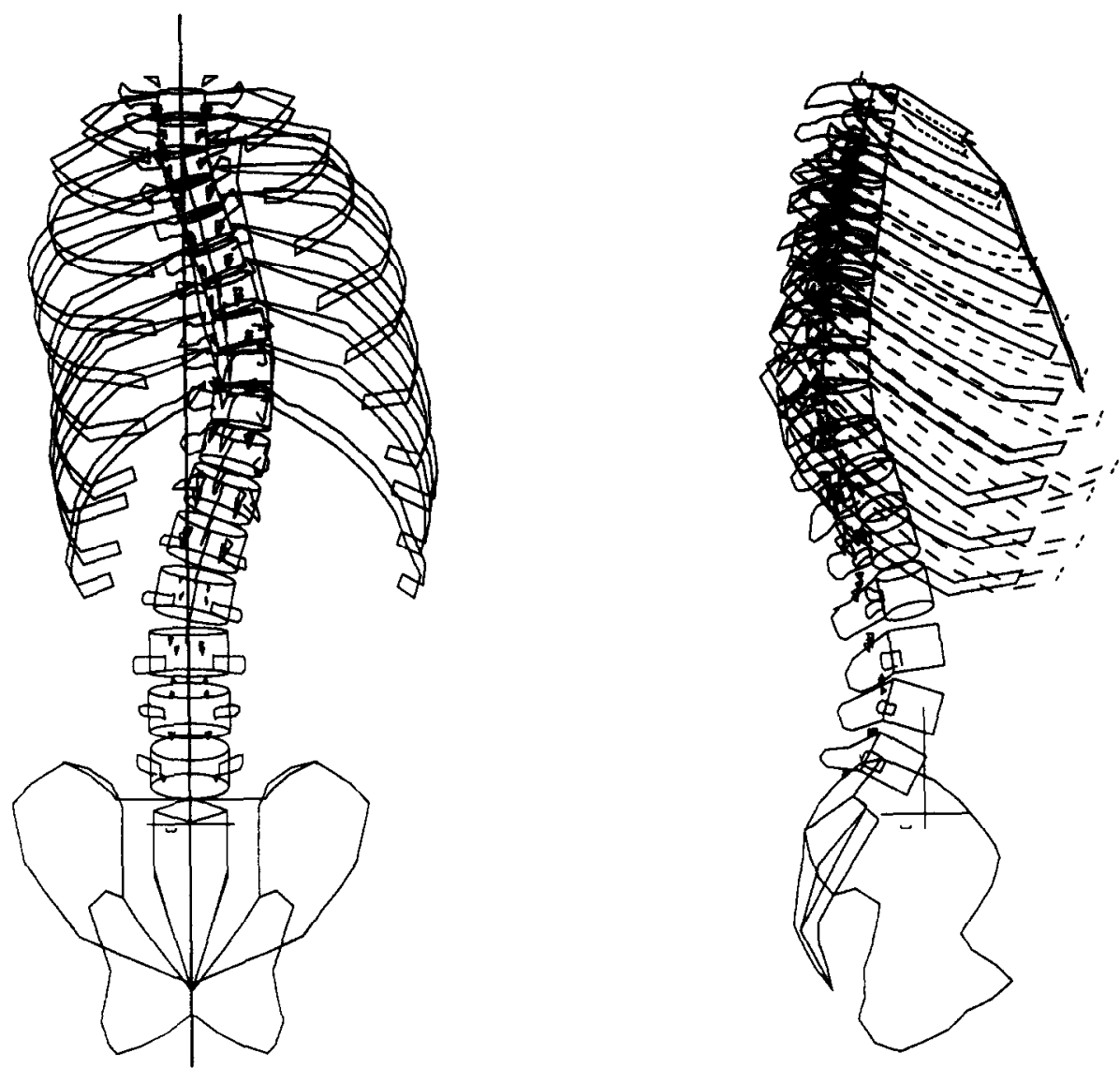

MT SPINE

Fig. 2. Mid-thoracic scoliosis (MT Spine). Posterior and right-side view of initial configuration. Curve data: Cobb angle $=42^{\circ}$; lateral offset of $\mathrm{T} 9=-4.0 \mathrm{~cm}$; axial rotation of $\mathrm{T} 9=-20^{\circ}$.

T9 level, a Cobb angle of $42^{\circ}$, an apical lateral offset of $4.0 \mathrm{~cm}$ to the right, and an apical axial rotation of $20^{\circ}$ clockwise in a superior view.

\section{Analysis}

The spine configuration changes resulting from the applied brace and muscle forces were evaluated in terms of the final Cobb angle and lateral offset of the apical vertebrae of the original curve and those for any secondary curves which developed. The final axial rotations of the apical vertebra of the original curve and the two adjacent vertebrae were also noted. Moreover, the recruitment patterns of brace and muscle forces and their corresponding magnitudes were noted.

\section{RESULTS}

Correction by brace forces

Application of passive brace forces had a substantial corrective effect on the Cobb angle and lateral alignment (Table 2, Fig. 3), even at non-maximal upper bounds. For example, with the $5.0 \mathrm{~N}$ bound, the initial Cobb angle was reduced to $27^{\circ}$ and the lateral offset of the apical vertebra was reduced to $-1.2 \mathrm{~cm}$ (objective $A$ ). However, under all circumstances examined, brace forces caused small left lumbar and left high thoracic secondary curves, and produced only modest spine de-rotations. The Cobb angle and apical lateral offset were significantly reduced independent of the objective function $(A, B$, or $C)$, but the axial derotation was dependent on the objective function; progressively greater axial de-rotation was achieved by using objective functions $Q_{B}$ and $Q_{C}$.

The locations of brace forces to optimally correct the model thoracic scoliosis are shown in Fig. 4. The optimal distribution of brace forces was: (1) primary forces on the convex side of the curve on ribs $7-10$; (2) counter forces on the concave side of the curve on ribs 5 and 6; and (3) counterforces on the concave side of the curve at the L2-L4 vertebral levels.

\section{Correction by muscle forces}

Use of active muscle forces also had a substantial corrective effect on the Cobb angle and lateral alignment (Table 3, Fig. 5), again, even at non-maximal 
Table 2. Final spine configurations resulting from correction by brace forces for increasing upper force bounds and objective functions $A, B, C$. Initial values are denoted by parentheses. Lum =lumbar, $\mathrm{HTh}=$ high-thoracic

\begin{tabular}{|c|c|c|c|c|c|c|c|c|c|}
\hline \multirow{3}{*}{$\begin{array}{l}\text { Force } \\
(\mathrm{N})\end{array}$} & \multicolumn{3}{|c|}{$\begin{array}{c}\text { Cobb angles } \\
\text { (degrees) }\end{array}$} & \multicolumn{3}{|c|}{$\begin{array}{l}\text { Lateral offsets } \\
\quad(\mathrm{cm})\end{array}$} & \multicolumn{3}{|c|}{$\begin{array}{l}\text { Axial rotations } \\
\text { (degrees) }\end{array}$} \\
\hline & Lum. & Primary & HTh & $\mathrm{L} 2$ & T9 & $\mathrm{T} 2$ & $\mathrm{~T} 8$ & T9 & T10 \\
\hline & $(0)^{*}$ & $(42)^{*}$ & $(0)^{*}$ & $(0.0)^{*}$ & $(-4.0)^{*}$ & $(0.0)^{*}$ & $(17)^{*}$ & $(20)^{*}$ & $(15)^{*}$ \\
\hline \multicolumn{10}{|c|}{ Objective $A$} \\
\hline 2.5 & 22 & 34 & 22 & 1.1 & -2.1 & 1.0 & 14 & 18 & 13 \\
\hline 5.0 & 22 & 27 & 24 & 1.3 & -1.2 & 1.1 & 12 & 16 & 12 \\
\hline 7.5 & 20 & 23 & 24 & 1.1 & -0.7 & 1.2 & 10 & 15 & 12 \\
\hline 10.0 & 19 & 21 & 24 & 0.9 & -0.6 & 1.2 & 10 & 15 & 12 \\
\hline \multicolumn{10}{|c|}{ Objective $B$} \\
\hline 2.5 & 22 & 34 & 22 & 1.1 & -2.2 & 1.1 & 11 & 15 & 11 \\
\hline 5.0 & 22 & 28 & 24 & 1.5 & -1.2 & 1.2 & 9 & 13 & 10 \\
\hline 7.5 & 21 & 24 & 24 & 1.3 & -0.8 & 1.2 & 8 & 13 & 10 \\
\hline 10.0 & 20 & 22 & 23 & 1.2 & -0.7 & 1.2 & 8 & 13 & 10 \\
\hline \multicolumn{10}{|c|}{ Objective $C$} \\
\hline 2.5 & 22 & 35 & 22 & 1.0 & -2.2 & 1.2 & 10 & 14 & 10 \\
\hline 5.0 & 22 & 28 & 23 & 1.5 & -1.3 & 1.1 & 8 & 13 & 9 \\
\hline 7.5 & 21 & 24 & 24 & 1.4 & -0.9 & 1.1 & 7 & 12 & 9 \\
\hline 10.0 & 21 & 23 & 24 & 1.3 & -0.8 & 1.1 & 7 & 12 & 9 \\
\hline
\end{tabular}

*Initial spine configuration.

Objective $A=10 \mathrm{f}(X)+1 \mathrm{f}(Y)+50 \mathrm{f}\left(\theta_{Y}\right)+2 \mathrm{f}\left(\theta_{Z}\right)$.

Objective $B=10 \mathrm{f}(X)+1 \mathrm{f}(Y)+50 \mathrm{f}\left(\theta_{Y}\right)+10 \mathrm{f}\left(\theta_{Z}\right)$

Objective $C=20 \mathrm{f}(X)+1 \mathrm{f}(Y)+90 \mathrm{f}\left(\theta_{Y}\right)+\operatorname{5of}\left(\theta_{Z}\right)$.

upper bounds. For example, with the $25 \mathrm{kPa}$ bound, the initial Cobb angle was reduced to $24^{\circ}$ and the lateral offset of the apical vertebra to $-1.0 \mathrm{~cm}$ (objective $A$ ). Moderate de-rotations were produced, but use of muscle forces still created small left lumbar and left high thoracic secondary curves. The Cobb angle and apical lateral offset again were significantly reduced independent of the objective function, and again, the axial de-rotation was dependent on the objective function weighting used.

The muscle groups and corresponding contraction intensities selected for optimal correction of the model
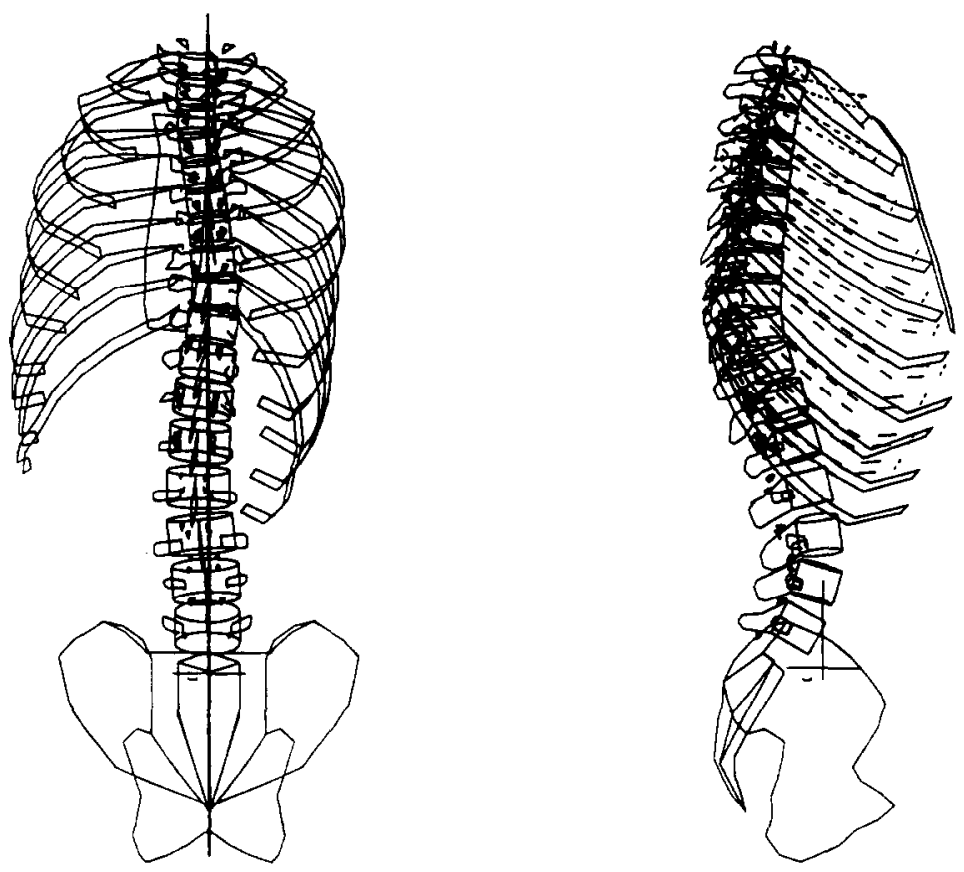

Fig. 3. Correction of model thoracic scoliosis by brace forces with an upper force bound of $10.0 \mathrm{~N}$ and using objective function $A$. See Table 2 for quantitative results. 

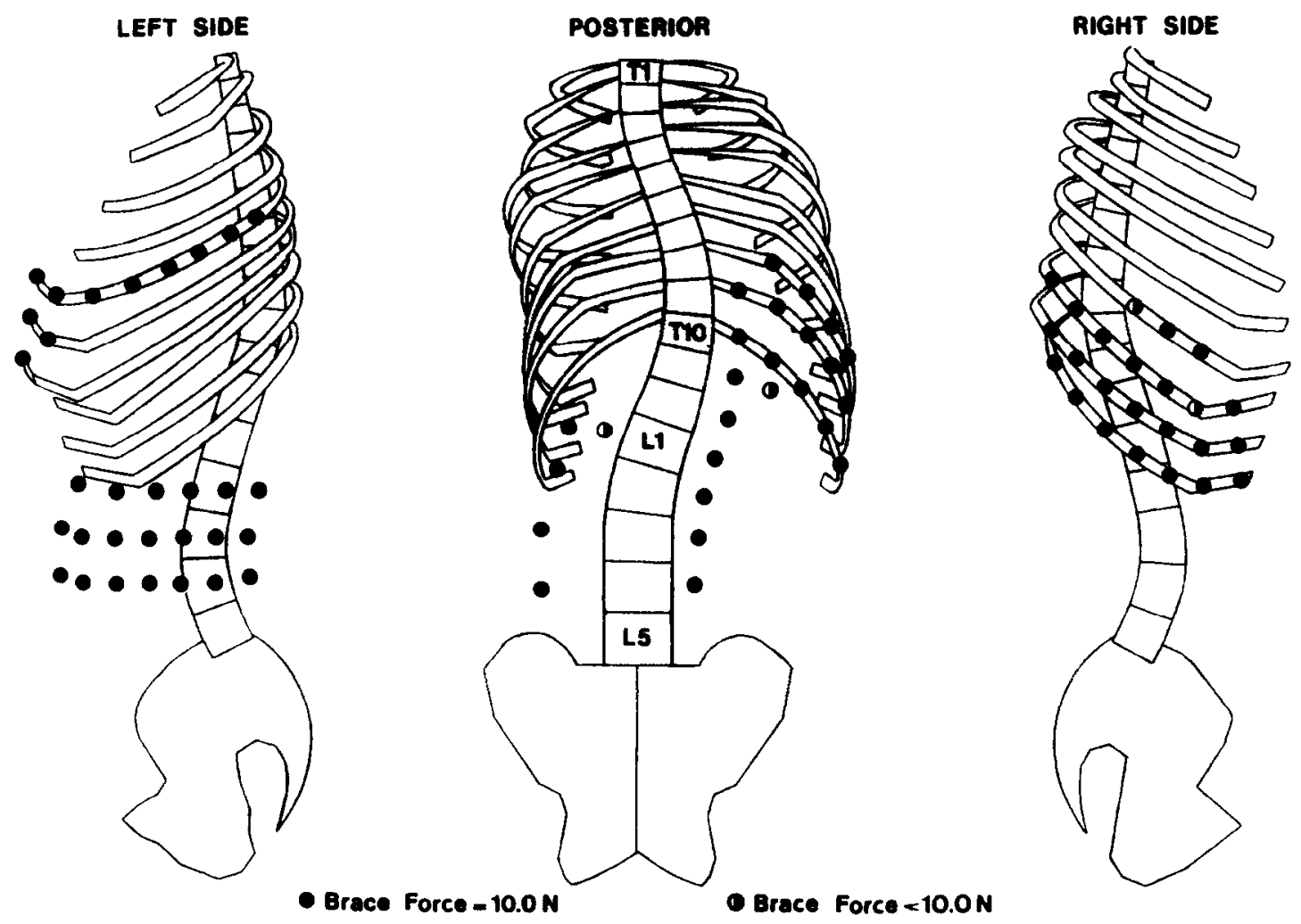

Fig. 4. Optimal distribution of brace forces for correction of the thoracic scoliosis. Each dot represents a $10.0 \mathrm{~N}$ point force exerted by the brace (objective function $A$ ).
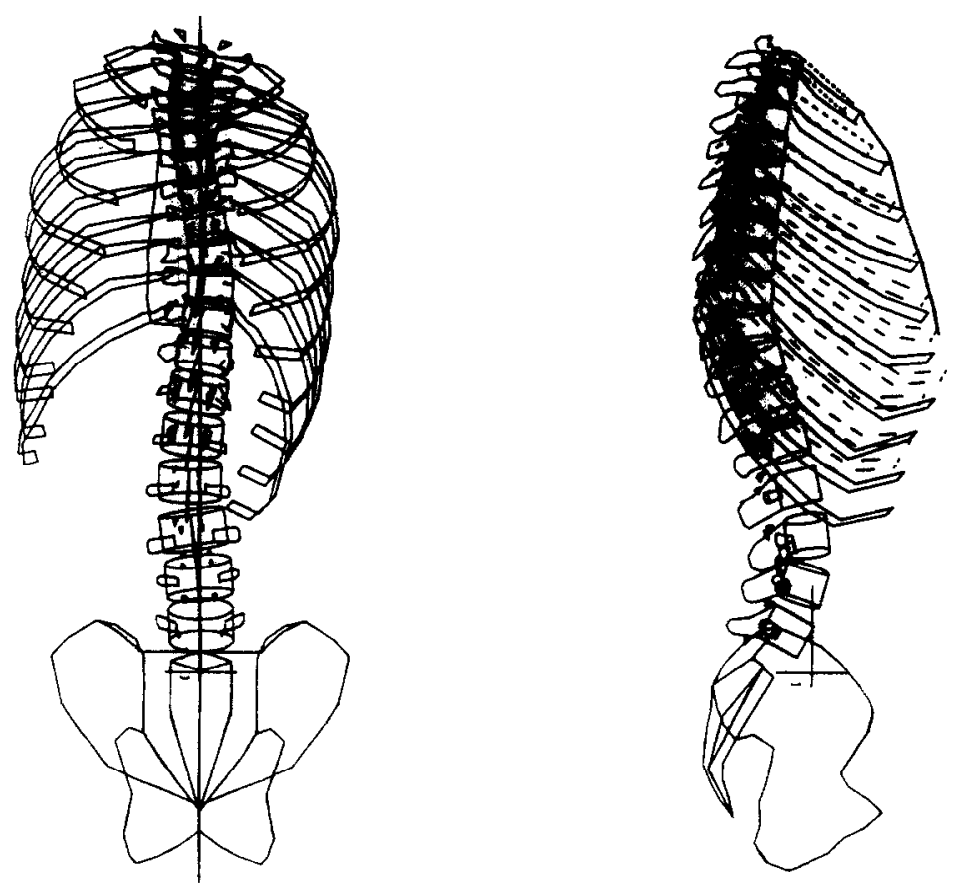

Fig. 5. Correction of the model thoracic scoliosis by muscle forces with an upper contraction intensity bound of $100 \mathrm{kPa}$ and using objective function $A$. See Table 3 for quantitative results. 
Table 3. Final spine configurations resulting from correction by muscle forces for increasing upper bounds on contraction intensity and objective functions $A, B$, and $C$. Initial values denoted by parentheses. Lum=lumbar, HTh $=$ high-thoracic

\begin{tabular}{|c|c|c|c|c|c|c|c|c|c|}
\hline \multirow{3}{*}{$\begin{array}{l}\text { Intensity } \\
\left(\mathrm{N} \mathrm{cm}^{-2}\right)\end{array}$} & \multicolumn{3}{|c|}{$\begin{array}{l}\text { Cobb angles } \\
\text { (degrees) }\end{array}$} & \multicolumn{3}{|c|}{$\begin{array}{l}\text { Lateral offsets } \\
\qquad(\mathrm{cm})\end{array}$} & \multicolumn{3}{|c|}{$\begin{array}{l}\text { Axial rotations } \\
\text { (degrees) }\end{array}$} \\
\hline & Lum. & Primary & HTh & L2 & T9 & $\mathrm{T} 2$ & $\mathrm{~T} 8$ & T9 & $\mathrm{T} 10$ \\
\hline & $(0)^{*}$ & $(42)^{*}$ & $(0)^{*}$ & $(0.0)^{*}$ & $(-4.0)^{*}$ & $(0.0)^{*}$ & $(17)^{*}$ & $(20)^{*}$ & $(15)^{*}$ \\
\hline \multicolumn{10}{|l|}{ Objective $A$} \\
\hline 2.5 & 22 & 32 & 21 & 1.0 & -2.1 & 0.7 & 12 & 16 & 12 \\
\hline 5.0 & 22 & 24 & 19 & 1.4 & -1.0 & 0.9 & 11 & 15 & 11 \\
\hline 7.5 & 19 & 21 & 18 & 1.1 & -0.7 & 1.0 & 8 & 14 & 11 \\
\hline 10.0 & 16 & 18 & 16 & 0.8 & -0.5 & 1.0 & 7 & 13 & 11 \\
\hline \multicolumn{10}{|l|}{ Objective $B$} \\
\hline 2.5 & 22 & 32 & 21 & 1.1 & -2.2 & 0.7 & 10 & 14 & 9 \\
\hline 5.0 & 22 & 24 & 21 & 1.5 & -1.1 & 0.9 & 8 & 12 & 8 \\
\hline 7.5 & 20 & 21 & 19 & 1.3 & -0.7 & 0.9 & 7 & 12 & 9 \\
\hline 10.0 & 18 & 19 & 17 & 1.2 & -0.7 & 0.8 & 7 & 12 & 9 \\
\hline \multicolumn{10}{|l|}{ Objective $C$} \\
\hline$\frac{2.5}{2.5}$ & 24 & 32 & 22 & 1.2 & -2.2 & 0.8 & 8 & 12 & 7 \\
\hline 5.0 & 22 & 24 & 21 & 1.5 & -1.1 & 0.9 & 7 & 11 & 7 \\
\hline 7.5 & 21 & 22 & 20 & 1.5 & -0.9 & 0.9 & 6 & 11 & 7 \\
\hline 10.0 & 20 & 21 & 19 & 1.3 & -0.8 & 0.8 & 6 & 10 & 6 \\
\hline
\end{tabular}

*Initial spine configuration

Objective $A=10 \mathrm{f}(X)+1 \mathrm{f}(Y)+50 \mathrm{f}\left(\theta_{Y}\right)+2 \mathrm{f}\left(\theta_{Z}\right)$.

Objective $B=10 \mathrm{f}(X)+1 \mathrm{f}(Y)+50 \mathrm{f}\left(\theta_{Y}\right)+10 \mathrm{f}\left(\theta_{Z}\right)$.

Objective $C=20 f(X)+1 \mathrm{f}(Y)+90 \mathrm{f}\left(\theta_{Y}\right)+50 \mathrm{f}\left(\theta_{Z}\right)$.

scoliosis are listed in column 2 of Table 1 and are shown graphically in Fig. 6. Typical responses employed the convex side erector spinae, lower latissimus, intercostals, external abdominal obliques, rectus abdominis, and transverse abdominal muscles. On the concave side, the upper trunk model muscles used were serratus, trapezius, pectorals, superior intercostals, superior thoracic erectors, and superior latissimus; and the lower trunk model muscles used were the external and internal abdominal obliques, transverse abdominals, and quadratus lumborum.

In summary, both brace and muscle forces were capable of substantial correction of a model thoracic scoliosis. Within the constraints imposed, muscle forces were somewhat more effective than brace forces in correcting all aspects of a thoracic scoliosis. The final spine configurations resulting from correction by brace and muscle forces are compared in Fig. 7. Since the focus of the optimization program was on correction of the spine, the rib cage has been omitted in these comparisons.

\section{DISCUSSION}

The results show the extent to which, under the optimal conditions outlined, brace and muscle forces are capable of correcting a model thoracic scoliosis. It is unknown if the muscle groups selected by the optimization program can contract simultaneously in vivo in the manner specified or if they can sustain their force over a period of time. The active correction theory of bracing assumes that the brace functions by stimulating the contraction of trunk muscles to correct a scoliosis. There is no substantial evidence to support this theory (Wynarsky, 1988). Recently, it was shown that there were no differences in trunk muscle myoelectric activity in patients when wearing and when not wearing a Boston brace (Wynarsky and Schultz, 1990). Thus, although the biomechanical analysis here shows that muscles have a capacity for substantial curve correction, at present there is no evidence that correction by active muscle contraction can be obtained other than through electrostimulation. However, scoliosis treatment by electrostimulation remains controversial, with some investigators reporting good short-term results (McCollough et al., 1980; Axelgaard and Brown, 1983; Axelgaard et al., 1983; Brown et al., 1984; Fisher et al. 1987; Katznelson and Nerubay, 1987), while others report poor results or question its effectiveness (Sullivan et al., 1986; Benson, 1987; O'Donnell et al., 1988).

The model curve corrections resulting from brace forces represent instantaneous elastic responses, and so correspond clinically to curve reductions upon immediate application of a brace. Watts et al. (1977) reported a mean instantaneous Boston brace reduction of initial $25^{\circ}$ curves to $10^{\circ}(60 \%)$ in 44 patients with a thoracolumbar scoliosis. In a study of 14 patients treated for adolescent idiopathic scoliosis by the Boston brace, Chase et al. (1989) reported a mean initial correction of $37+21 \%$ for thoracic curves and $36+22 \%$ for lumbar curves. Most clinical reports document the maximum Cobb angle reduction achieved during the treatment period (Emans et al., 

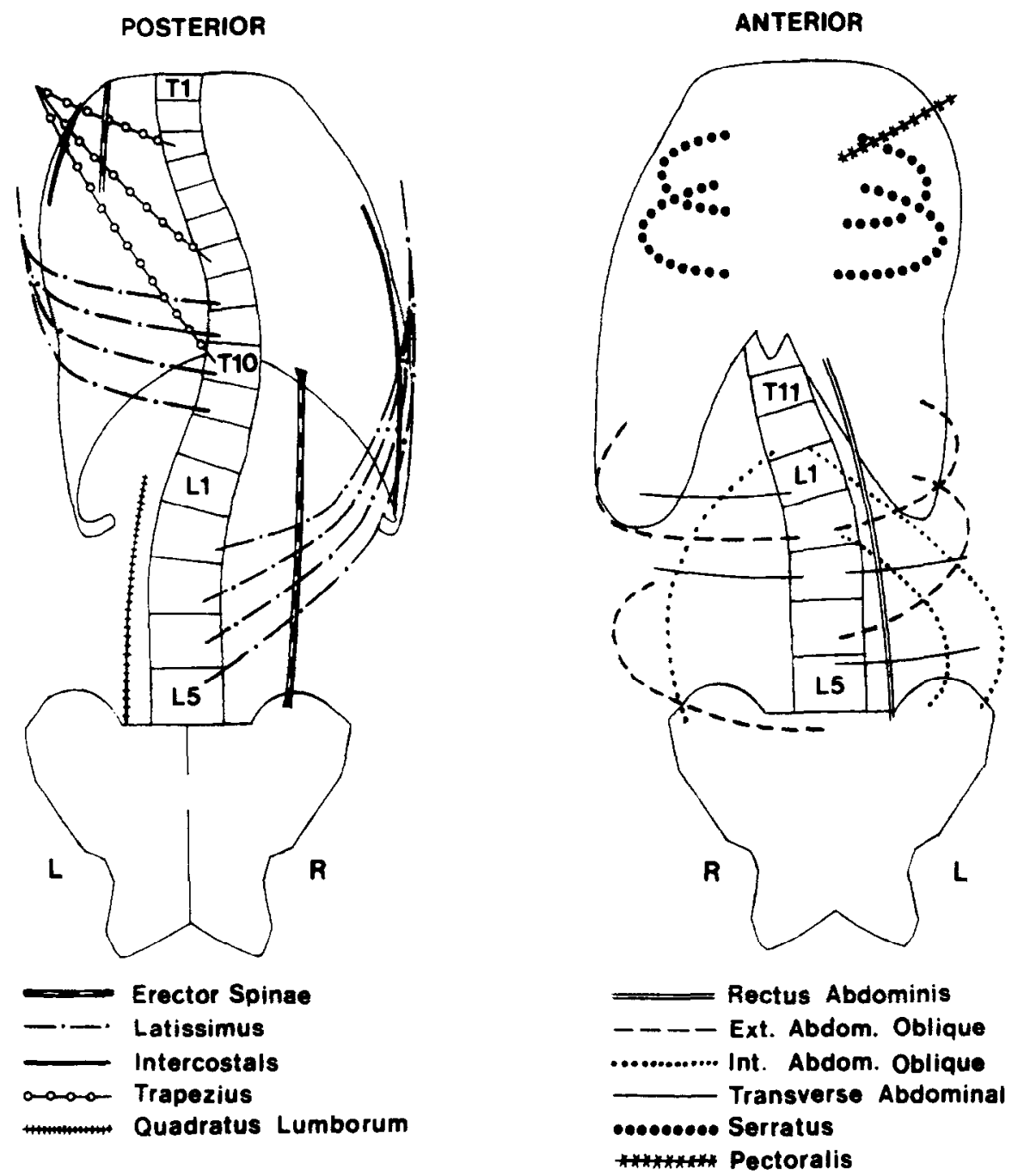

Fig. 6. Muscle groups selected by the optimization technique to achieve optimal correction of the thoracic scoliosis. Specific muscle slips and their corresponding contraction intensity magnitudes are listed in Table 1, column 3.

1986; Gardner et al., 1986; Jonasson-Rajala et al., 1984; Willner, 1984; Laurnen et al., 1983; Uden and Willner, 1982). These show thoracic curve reductions, on average, of approximately $44 \%$. In the present study, the initial model Cobb angle, which was considerably larger than those studied by Watts et al., was reduced $50 \%$ by optimal brace forces and $57 \%$ by optimal muscle contractions.

Secondary lateral curves in the high-thoracic and lumbar regions were produced by the optimal correction schemes. This finding is also consistent with clinical observations. Jonasson-Rajala et al. (1984) reported that the Boston brace treatment may cause secondary curves of approximately $15-19^{\circ}$. In the present study, the secondary curve magnitudes were only slightly larger than those reported with correction by brace forces (Table 2) and about the same magnitude with correction by muscle forces (Table 3 ).

Vertebral body lateral offsets and lateral tilts were closely related, but neither was substantially related to the axial rotations of the spine. In general, solutions which emphasized correction of the Cobb angle and lateral alignment did not yield substantial axial derotations of the vertebrae, and vice versa. This implies that correction of the rib cage deformity (associated with vertebral rotations) is not necessarily coupled with the Cobb angle. Weisz et al. (1989) showed that bracing may improve the cosmetic appearance of a scoliotic back, although the underlying curve remains unchanged. In 32 patients treated with the Boston brace, back surface shape improved in $41 \%$ of the patients, while roentgenographic improvement occurred in only $9 \%$.

Few clinical investigations of bracing report axial de-rotations. Aaro et al. (1981) found a mean apical de-rotation of $38 \%$ in 33 patients with thoracic idiopathic scoliosis. The present study found a reduction of $40 \%$ when brace forces and objective weighting $C$ were used. Saraste and Ostman (1986) found a mean de-rotation of $14^{\circ}\left(0-38^{\circ}\right.$ range $)$ in 21 patients treated 


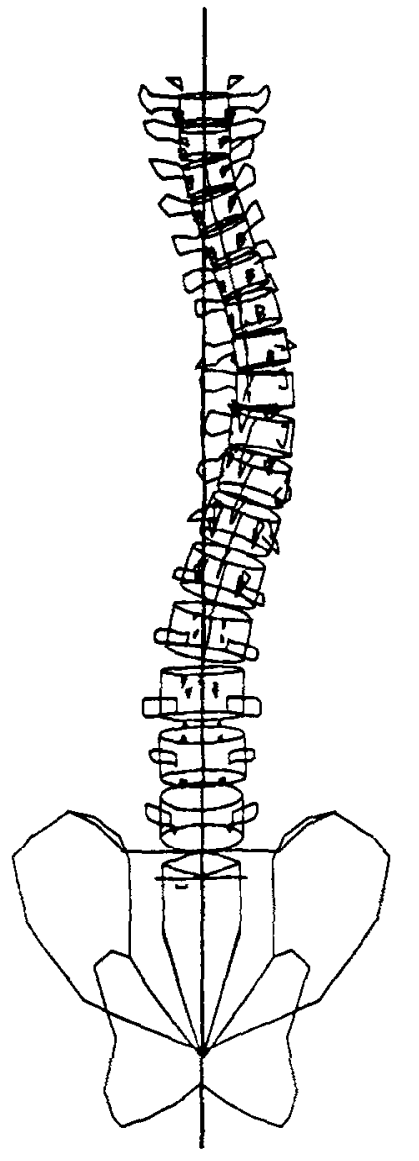

THORACIC SCOLIOSIS

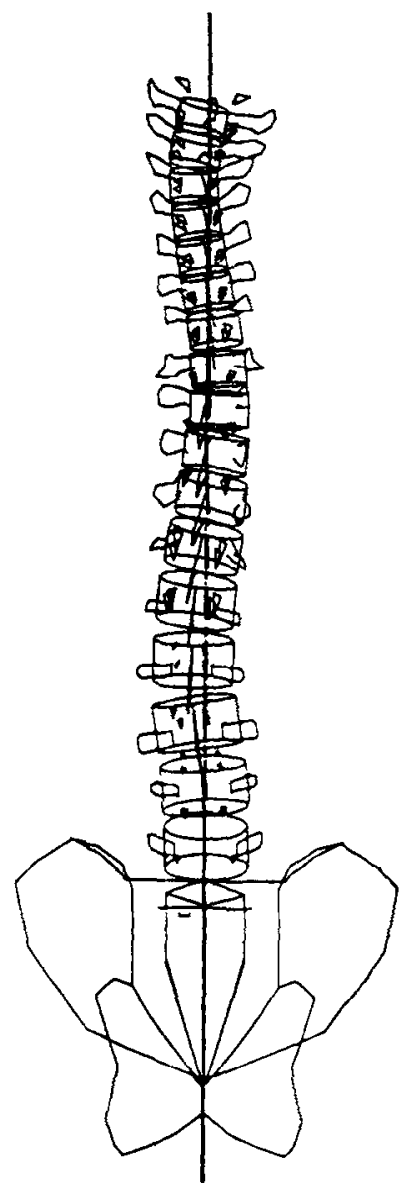

BRACE FORCES

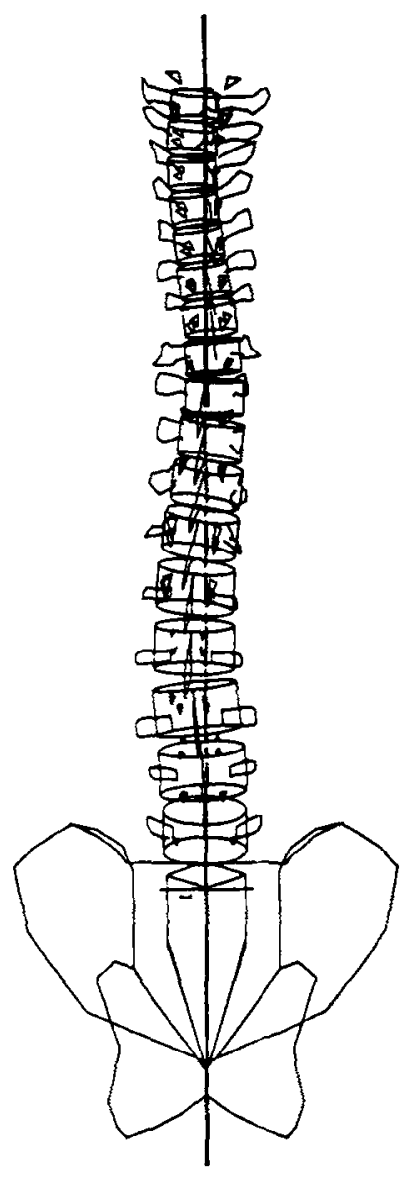

MUSCLE FORCES

Fig. 7. Comparison of thoracic curve correction by brace and muscle forces. Rib cage omitted for clarity.

with the Boston brace, but they did not report initial axial rotations.

The structural model assumed, for computational tractability, both geometric and material linearity. Wynarsky (1988) explains why neither assumption was likely to qualitatively bring into question any study findings. Model spine configuration changes were usually small and only the deformable elements connecting the ribs to the sternum underwent large deformations. Model geometric changes did not relate linearly to applied forces because of the inequality constraints.

There is substantial clinical controversy regarding the use of bracing for the treatment of idiopathic scoliosis. The curve reductions achieved under optimal biomechanical conditions were only slightly larger than the largest reductions ('best-in-brace') achieved clinically by brace treatment. Thus, the outcomes resulting from optimal brace treatment could not be expected to be much different from those obtained with present bracing protocols. Clinically, long-term brace treatment results show that, on aver- age, the final post-treatment Cobb angles are nearly the same as the pre-bracing Cobb angles (Mellencamp and Blount, 1986; Emans et al., 1986; Bassett et al., 1986; Peltonen et al., 1988; Edgar and Mehta, 1988; Andrews and MacEwen, 1989; Montgomery et al., 1990; Piazza and Bassett, 1990). Thus, even optimal bracing should not be expected to produce either permanent or complete curve correction.

In summary, a computational scheme for optimizing responses of skeletal configuration models has been presented. Use of the scheme was illustrated by studies of non-surgical correction of a model thoracic scoliosis. The outcomes of the model study were in good agreement qualitatively with clinical outcomes, but quantitatively tended to be somewhat better. Even under optimal conditions it is unlikely that scoliosis can be fully corrected by passive brace forces or active trunk muscle contractions.

This optimization program has been used to study thoracolumbar double curve, single lumbar curve, and thoracic double curve spine morphologies (Wynarsky, 1988). This scheme could also be used to determine 
forces necessary to correct the rib cage deformity as well as the spinal deformity, and other spine deformities such as kyphosis, lordosis, and lordoscoliosis.

Acknowledgement-The support of Public Health Service Grant AR 33948 for this research is gratefully acknowledged.

\section{REFERENCES}

Aaro, S., Burstrom, R. and Dahlborn, M. (1981) The derotating effect of the Boston brace. A comparison between computer tomography and a conventional method. Spine 6, 477-482.

Andrews, G. and MacEwen, G. D. (1989) Idiopathic scoliosis. An 11-year follow-up study of the role of the Milwaukee brace in curve control and trunco-pelvic alignment. Orthopedics 12, 809-816.

Andriacchi, T., Schultz, A., Belytschko, T. and DeWald, R. (1976) Milwaukee brace correction of idiopathic scoliosis: a biomechanical analysis and a retrospective study. J. Bone Jt Surg. 58, 806-815.

Andriacchi, T., Schultz, A., Belytschko, T. and Galante, J. (1974) A model for studies of mechanical interactions between the human spine and rib cage. J. Biomechanics 7 , 497-507.

Axelgaard, J. and Brown, J. C. (1983) Lateral electrical surface stimulation for the treatment of progressive idiopathic scoliosis. Spine 8, 242-260.

Axelgaard, J., Nordwall, A. and Brown, J. C. (1983) Correction of spinal curvatures by transcutaneous electrical muscle stimulation. Spine 8, 463-481.

Bader, D. and Gant, C. (1985) Effects of prolonged loading on tissue viability. Oxford Orthop. Engng Centre Rep. 12, 33-34.

Bassett, G. S., Bunnell, W. P. and MacEwen, G. D. (1986) Treatment of idiopathic scoliosis with the Wilmington brace. Results in patients with a twenty to thirty-nine degree curve. J. Bone Jt Surg. (Am) 68, 602-605.

Belytschko, T., Andriacchi, T., Schultz, A. and Galante, J. (1973) Analog studies of forces in the human spine: computational techniques. $J$. Biomechanics 6, 361371 .

Benson, D. R. (1987) Idiopathic scoliosis. The last ten years and state of the art. Orthopedics 10, 1691-1698.

Blount, W. and Moe, J. (1973) The Milwaukee brace. Williams and Wilkins, Baltimore.

Bobechko, W. P., Herbert, M. A. and Friedman, H. G. (1979) Electrospinal instrumentation for scoliosis: current status. Orthop. Clin. North Am. 10, 927-941.

Brown, J. C., Axelgaard, J. and Howson, D. C. (1984) Multicenter trial of a noninvasive stimulation method for idiopathic scoliosis. A summary of early treatment results. Spine 9, 382-387.

Bunch, W. (1975) The Milwaukee brace in paralytic scoliosis. Clin. Orthop. 110, 63-68

Chase, A., Bader, D. and Houghton, G. (1989) The biomechanical effectiveness of the Boston brace in the management of adolescent idiopathic scoliosis. Spine 14, 636-642.

Edgar, M. A. and Mehta, M. H. (1988) Long-term follow-up of fused and unfused idiopathic scoliosis. J. Bone Jt Surg. (Br) 70, 712-716.

Emans, J., Kaelin, A., Bancel, P., Hall, J. and Miller, M. (1986) The Boston bracing system for idiopathic scoliosis. Follow-up results in 295 patients. Spine 11, 792-801.

Fisher, D. A., Rapp, G. F. and Emkes, M. (1987) Idiopathic scoliosis: transcutaneous muscle stimulation versus the Milwaukee brace. Spine 12, 987-991.

Gardner, A., Burwell, R., Wozniak, A., MacPherson, I., Denn, P.. Pursell, L. and Pursell, A. (1986) Some beneficial effects of bracing and a search for prognostic indıcators in idiopathic scoliosis. Spine 11, 779.

Ghista, D. N., Viviani, G. R., Subbaraj, K., Lozada, P. J. Srinivasan, T. M. and Barnes, G. (1988) Biomechanical basis of optimal scoliosis surgical correction. J. Biomechanics 21, 77-88.

Gunnoc, B. A. (1990) Adolescent idiopathic scoliosis. Orthop. Rev. 19, 35-43.

Ikai, M. and Fukunaga, T. (1968) Calculation of muscle strength per unit cross-sectional area of human muscle by means of ultrasonic measurement. Int. Z. Angew. Physiol. 26, 26-32.

Jonasson-Rajala, E., Josefsson, E., Lundberg, B. and Nilsson, H. (1984) Boston thoracic brace in treatment of idiopathic scoliosis. Initial correction. Clin. Orthop. 183, 37-41.

Katznelson, A. M. and Nerubay, J. (1987) The electrospinal treatment of idiopathic scoliosis in the adolescent. Orthop. Rev. 16, 855-860.

Kehl, D. L. and Morrissy, R. T. (1988) Brace treatment in adolescent idiopathic scoliosis. An update on concepts and technique. Clin. Orthop. 229, 34-43.

Keller, R. B. (1989) Nonoperative treatment of adolescent idiopathic scoliosis. Instr. Course Lect. 38, 129-135.

Laurnen, E., Tupper, J. and Mullen, M. (1983) The Boston brace in thoracic scoliosis. A preliminary report. Spine $\mathbf{8}$, 388-395.

Lindbeck, L. (1985) Analysis of functional scoliosis by means of an anisotropic beam model of the human spine. $J$. biomech. Engng 107, 281-285.

Lonstein, J. E. and Winter, R. B. (1988) Adolescent idiopathic scoliosis. Nonoperative treatment. Orthop. Clin. North Am. 19, 239-246.

McCollough, N., Friedman, H. and Bracale, R. (1980) Surface electrical stimulation of the paraspinal muscles in the treatment of idiopathic scoliosis. Orthop. Trans. 4, 29

Mellencamp, D. and Blount, W. (1986) Late results revisited. Spine 11, 805-806.

Moe, J. and Kettleson, D. (1970) Idiopathic scoliosis: analysis of curve patterns and the preliminary results of Milwaukee brace treatment in 169 patients. J. Bone Jt Surg. 42A, $1509-1533$.

Montgomery, F., Willner, S. and Appelgren, G. (1990) Longterm follow-up of patients with adolescent idiopathic scoliosis treated conservatively: an analysis of the clinical value of progression. J. Pediat. Orthop. 10, 4852.

Murtagh, B. and Saunders, M. (1978) Large-scale linearly constrained optimization. Math. Prog. 14, 41-72.

Murtagh, B. and Saunders, M. (1983) Minos5.0 User's Guide. Technical Report SOL83-20. Systems Optimization Laboratory, Stanford University.

O'Donnell, C. S., Bunnell, W. P., Betz, R. R., Bowen, J. R. and Tipping, C. R. (1988) Electrical stimulation in the treatment of idiopathic scoliosis. Clin. Orthop. 229, 107-113.

Patwardhan, A., Bunch, W., Meade, K., Vanderby, R. and Knight, G. (1986) A biomechanical analog of curve progression and orthotic stabilization in idiopathic scoliosis. J. Biomechanics 19, 103-117.

Peltonen, J., Poussa, M. and Ylikoski, M. (1988) Three-year results of bracing in scoliosis. Acta orthop. scand. 59, 487-490.

Piazza, M. R. and Bassett, G. S. (1990) Curve progression after treatment with the Wilmington brace for idiopathic scoliosis. J. Pediat. Orthop. 10, 39-43.

Portillo, D., Sinkora, G., McNeill, T., Spencer, D. and Schultz, A. (1982) Trunk strengths in structurally normal girls and girls with idiopathic scoliosis. Spine 7, 551-554.

Saraste, H. and Ostman, A. (1986) Stereophotogrammetry in the evaluation of the treatment of scoliosis. Int. Orthop. 10 , 63-67.

Schultz, A., Belytschko, T., Andriacchi, T. and Galante, J. (1973b) Analog studies of forces in the human spine: mechanical properties and motion segment behavior. $J$. Biomechanics 6, 373-383. 
Schultz, A., Benson, D. and Hirsch, C. (1974a) Forcedeformation properties of human ribs. J. Biomechanics 7 , 303-309.

Schultz, A., Benson, D. and Hirsch, C. (1974b) Forcedeformation properties of human costo-sternal and costovertebral articulations. J. Biomechanics 7, 311-318.

Schultz, A., Haderspeck, K. and Takashima, S. (1981) Correction of scoliosis by muscle stimulation: a biomechanical analysis. Spine 6, 468-476.

Schultz, A. and Hirsch, C. (1973a) Mechanical analysis of Harrington rod correction of idiopathic scoliosis. J. Bone Jt Surg. 55A, 983-992.

Sullivan, J. A., Davidson, R., Renshaw, T. S., Emans, J. B., Johnston, C. and Sussman, M. (1986) Further evaluation of the Scolitron treatment of idiopathic adolescent scoliosis. Spine 11, 903-906.

Takashima, S., Singh, S., Haderspeck, K. and Schultz, A. (1979) A model for semi-quantitative studies of muscle actions. J. Biomechanics 12, 929-939.

Uden, A. and Willner, S. (1982) Initial correction with the Boston brace. Acta. orthop. scand. 53, 907-911.

Watts, H., Hall. J. and Stanish, W. (1977) The Boston brace system for the treatment of low thoracic and lumbar scoliosis by the use of a girdle without superstructure. Clin. Orthop. 126, 87-92.

Weisz, I., Jefferson, R. J., Carr, A. J., Turner-Smith, A. R., McInerney, A. and Houghton, G. R. (1989) Back shape in brace treatment of idiopathic scoliosis. Clin. Orthop. 240, 157-163.

Willner, S. (1984) Effect of the Boston thoracic brace on the frontal and sagittal curves of the spine. Acta. orthop. scand. $55,457-460$.

Wynarsky G. (1988) Biomechanics of bracing in idiopathic scoliosis. Ph.D. dissertation, University of Michigan.

Wynarsky, G. and Schultz, A. B. (1990) Trunk muscle activities in braced scoliosis patients. Spine 14, 1283-1286. 